\title{
Preparation and mechanism analyses of a new corn seed coating agent
}

\author{
Defang Zeng*, Xinrong Luo
}

School of Resource and Environmental Engineering, Wuhan University of Technology, Hubei Key Laboratory of Mineral Resources Processing and Environment, Wuhan, China; ${ }^{*}$ Corresponding Author: $\underline{\text { df5152@163.com }}$

Received 9 September 2011; revised 24 October 2011; accepted 31 October 2011.

\begin{abstract}
Due to the severity of the disease and yield losses of corn, this study had achieved a novel corn seed coating agent which was prepared with polysaccharide, fertilizer, microelement and other assistants as raw materials. The dilution and the $\mathrm{pH}$ value of the corn seed coating agent, were studied. And the biological toxicity and potential hazards of the agent to environmental protection were assessed. Over the whole trial, the best formula and optimum conditions of a new corn seed coating agent were determined. Also results indicated that compared with the traditional one Jinong No. 4, yields of corn was increased over $9.5 \%$, but cost was reduced over $18.75 \%$. To sum up, this agent self-made had three primary characteristics of high yield, less cost and friendly environment. So it had an important value of application and promotion in main production zone of corn and can bring us obvious economic and environmental benefits.
\end{abstract}

Keywords: Coating; Germination Rate; Inhibitory Rate; Antifeedant Rate; High Yield; Friendly Environment

\section{INTRODUCTION}

Corn is one of the major crops in China, but in recent years, the soil-borne of corn has been aggravated year by year, and corn yields decreased obviously. So the soilborne of corn has become one of the main factors of corn yields and quality [1,2]. To protect corn from underground pest, provide the source of fertilizer, and increase yields of corn, seed-coating is an effective technology and has been widely applied for crop protection [3]. Studies have shown that a seed coating is effective in preventing and controlling mould-induced diseases and pests causing them, promoting seedling growth, and increasing yields $[4,5]$.
Since the seed coating agent for rain-fed crops first in the 1930s, the research and development of the seed coating agent has been rapid during the past two decades and has provided an economical approach to seed enhancement, especially for larger seeded agronomic and crops [6-8]. However, the conventional toxic seed coating agent currently used such as carbofuran and thiram unavoidably brought serious harm to the environment and human and make the development of ecoagricultural practices impossible [9-11]. Studies showed that only 7 milligrams of carbofuran can kill a person. In addition, it leaves a Long-term pollution, eliminated difficultly from the environment, and becomes a great hidden danger in China's ecological agriculture [12,13].

The dire threat of current conventional toxic seed coating agent forces to seek for a safe and environ- mentally friendly corn seed-coating agent to resolve the current agricultural and environmental issue. After years of research, the novel seed coating agent (short for LSCA) instead of conventional toxic fungicide, was achieved through advanced biological chelating technology, which prepared with natural polysaccharide as the main material and high-activity plant growth regulator as the auxiliary material. Compared with a conventional seed coating (Jinong No. 4), the effect of LSCA on the resistance to smut fungus, seed germination, and corn yield, as well as its toxicity was investigated. Yields of corn was increased over $9.5 \%$, but cost was reduced over $18.75 \%$. With the application of the new coating agent, corn seed-coating agent has better quality and properties such as high yield, low cost, friendly environment, and would have significant economic and environmental benefits.

\section{MATERIALS AND METHODS}

\subsection{Materials}

\subsubsection{Major Apparatuss and Glassware}

The major instruments and glassware used in present study were electron constant speed mixer GS28B (Shang- 
hai Anting Electronic Instruments Plant, Shanghai, China), high pressure steam sterilizer YXQ-SG46-48SA (Shanghai Boyi Industry Co. Ltd., Shanghai, China), constant temperature and humidity incubator WS-01 (Hubei Huangshi Hengfeng Medical Instrument Co., Ltd., Hubei, China), electronic balance (FA2004, ShanghaiYuefeng Instrument Appearance, Ltd., Shanghai, China), warm up hygrometer STH950 (Summit, USA), biological microscope BX41-12HO2 (Olympus Corp., Japan) and petri dishes (90 cm dia., Shanghai Yuejin Medical Treatment Instrument Plant, Shanghai, China). 24 Orifices of plate.

\subsubsection{Major Chemicals and Reagents}

The major chemicals and reagents used in present study were polysaccharide (PC, self-made in lab), film-forming agent, polyethylene glyco (self-made in lab), the agriculture regulates, acetic acid, carbamide, natrium hydroxydatum, violet pigment (Guangdong shantou Ming frideric food additive Co., LTD), sand, The conventional corn seed coating agent Jinong No. $4^{\circledR}$ (Hubei Provincial Seed Group Co., Ltd., China) (Prefecture Seed Science and Technology Development, Ltd., Henan, China), Artificial feed, Smut fungus (North Coating Agents Factory, Tianjin, China), Corn seeds (China Jilin Seed Co.).

\subsubsection{Experimental Animals}

Cutworm (the consistent growth) (provided by Heilongjiang Agriculture University, Sprague-Dawley rats (20 males, 20 females; $200 \pm 12$ g) (Animal Testing Center of Tongji Medical College of Huazhong University of Science and Technology).

\subsection{Experiment Methods}

The experiment stepwise development and technique route of corn seed coating agent was showed in the Figure 1. According to three principles of cheapness, environmental protection, high efficiency, a number of the recipes of the corn seed coating agents were designed to prevent seedling and increasing yields. Once all the major performance parameters of agents made in lab exceed those of the traditional one Jinong No. 4, we optimized further on the basis of experiment to get the best recipe, then carried the field text, to determine the best formula of agent with a high cost performance and environmental friendship.

\subsubsection{Comparative Experiment of the Corn Seed Coating Agent in the Laboratory}

As stated by the manufacturer of Seafresh Chitosan (Lab) Co. Ltd., China, the natural polysaccharide with a molecular weight of from 20 to $1500 \mathrm{KD}$ and deacetylation degree of from $80 \%$ to $90 \%$, was prepared as: 1 wt $\%$ acetic acid to dissolve polysaccharide completely to a final concentration $1 \mathrm{wt} \%$ under stirring at $25^{\circ} \mathrm{C}$ for approximately $4 \mathrm{~h}$.

The optimal coating formulation was determined through orthogonal test. Aqueous solutions of fertilizer, microelement, ethylene glycol, film former and crocuses red were prepared respectively at a certain concentration. After mixing every component completely at room temperature.

Concrete experimental process are as follows:

\subsubsection{Test of Seed Germination}

Comparative experiment of the corn seed coating agent in the laboratory was as follows: the same corn seeds were coated with the new seed coating agents (A-E) and the conventional one (Jinong No. 4) respectively, and then put in the constant temperature and humidity incubator under the same condition of the constant temperature $28^{\circ} \mathrm{C} \pm 1^{\circ} \mathrm{C}$ and the constant humidity 85\%. Experimental results of the germination tendency and germination rate should be observed and compared every day. Each treatment was replicated 3 times.

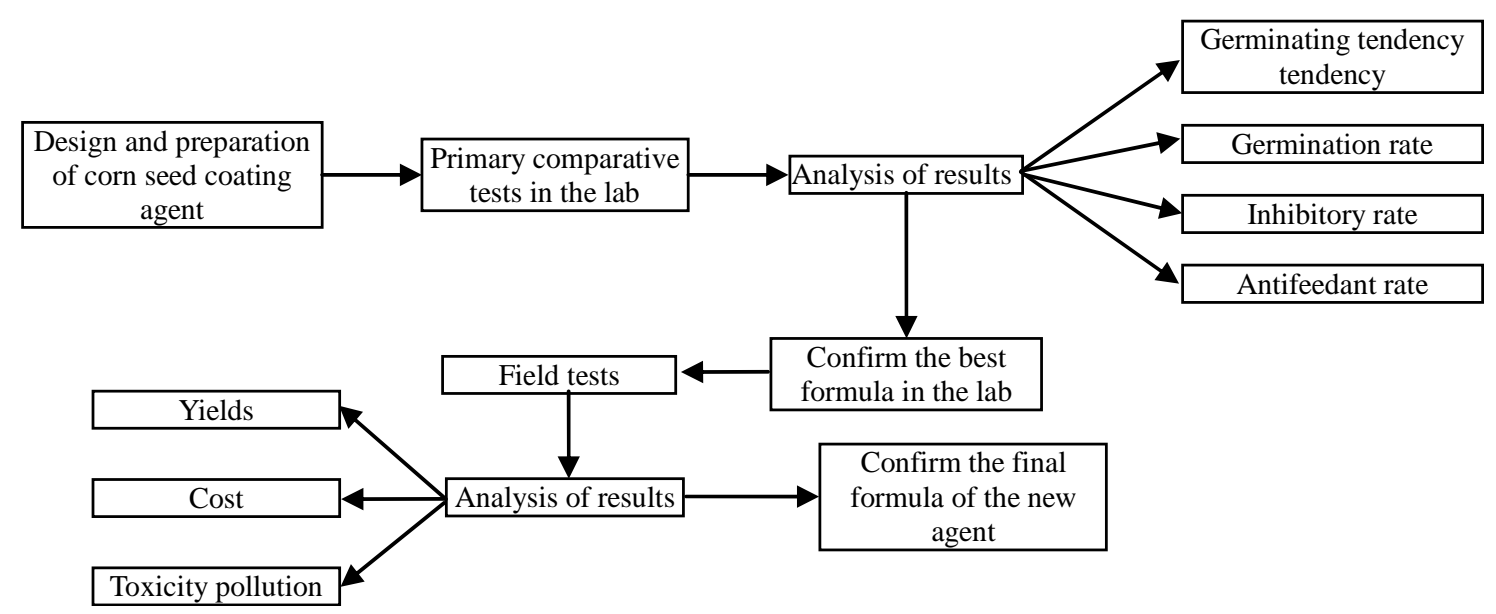

Figure 1. The experiment stepwise development and technique route of corn seed coating agent. 
According to the seed test procedures methods of international seed association (ISTA) [14], germinating tendency (GT) was calculated on the 4th day and germination rate (GR)was calculated on the 7th day. The calculation formulas were as follow:

$$
\begin{aligned}
& \text { GT }(\%)=\left(G_{3} / S\right) \times 100 \\
& \text { GR }(\%)=\left(G_{7} / S\right) \times 100
\end{aligned}
$$

where $G_{3}$ is the number of germinated seeds on the third day; $G_{7}$ is the number of germinated seeds on the seventh day; $\mathrm{S}$ is the number of total seeds investigated.

\subsubsection{Antibacterial Experiment in the Lab}

According to microbiological test requirements for inhibitory rate trial, the Setosphaeria turcica blocked 5 $\mathrm{mm}$ were inoculated to agar which was sterilized with a high-pressure steam and mixed with different agents, water as to control respectively, and then cultivated at $25^{\circ} \mathrm{C}$ for 2 days [15]. The tests were repeated 3 times and recorded the diameter using cross measuring method. The following formula was used to calculate the inhibitory rate of corn seed coating agents.

$$
\operatorname{IR}(\%)=\left[\left(\mathrm{D}_{0}-\mathrm{D}\right) / \mathrm{D}_{0}\right] \times 100
$$

where IR is Inhibitory rate; $D_{0}$ is colonies diameter in the control petri dish, and $\mathrm{D}$ is the colonies diameter in the test petri dish.

Once all the major performance parameters of agents made in lab exceed those of the traditional one, then we optimized further on the basis of experiment to get the best recipe, named after LSCA, repeated the aboved and stability experiment.

\subsubsection{Antifeedant Test of Pests in the Lab}

According to the guideline for laboratory bioassay of pesticides, the antifeeding effect of LSCA was studied with the artificial mixed feeding method The process of the antifeeding test was as follows: a certain amount of artificial feed mixed a certain amount of LSCA, the proportion (w/w) were $5 \%, 10 \%, 15 \%$, and an untreated group (CK) as control was designed. Then the feeds above and the consistent growth cutworms were put into the Orifices plates. Cutworms were feeded in the incubator at a temperature of $25^{\circ} \mathrm{C} \pm 1^{\circ} \mathrm{C}$, and relative humidity of $75 \%-85 \%$. After $48 \mathrm{~h}$ the remaining feeds (control and treated) were weighted, the test was valid only the mortality of larvae within $5 \%$. Every text replicated three times the formula is as follows [16]:

$$
\text { AR }(\%)=\left[\left(\mathrm{W}_{0}-\mathrm{W}\right) / \mathrm{W}_{0}\right] \times 100
$$

where AR is Antifeedant rate; $\mathrm{W}_{0}$ is the weight of control feed and $\mathrm{W}$ is the weight of feed treated by corn seed coating agent.

\subsubsection{The Security Test}

According to the toxicological test methods of pesticides for registration, the toxic effect of LSCA and Jing No. 4 were studied with the $\mathrm{LD}_{50}$ (the median lethal dose) method. In the study, the rats were fasted overnight, then treated at various dosages of LSCA and Jinong No. 4, by oral ingestion and skin infection respectively. The toxic symptoms of rats and the median lethal dose $\left(L_{50}\right)$ were recorded after 14 days. According to the results of the toxicity test, the difference of toxicity LSCA and Jinong No. 4 was estimated.

\subsubsection{Field Trials}

Through the above formula and the experimental results, we calculated the germinating tendency and germination rate, inhibitory rate, antifeedant rate etc., and finally the best formulation was evaluated in the field.

Field trial was carried out to verify further whether the efficacy of (LSCA) in the laboratory was stabilized, and the effect on the yield was higher than that of the traditional one. In this test, the method of seed treatment was the same as that in the laboratory experiment, the corn seeds were coated with LSCA and Jinong No. 4 in the proportion of 1:50 (w/w).The experiment was conducted at Hubei Provincial Seed Group Company. The experiments were designed as a randomized block, and each treatment was replicated three times.

\subsubsection{Statistic Alanalysis}

Analyses of variance (ANOVA) and Duncan means comparisontest with asignificance levelof 0.05 were applied.

\section{RESULTS AND DISCUSSION}

\subsection{Results}

\subsubsection{Primary Experiment Results in the Laboratory}

The primary purpose was to select the best environmentally friendly corn seed coating agent, the priceperformance ratio of which preponderated over that of Jinong No. 4. Primary experiment results in the laboratory were showed in Table 1, corn seed coating agents A-H were prepared-self, the traditional one Jinong No. 4, CK uncoated seed as control.

It can be seen from Table 1, different agents had different influences on corn seedling growth, and the main indexes of B-E exceeded over Jinong No. 4. It can be seen that $\mathrm{E}$ had a most effect on germinating tendency, germination rate, inhibitory rate, and enhanced by $9.4 \%$, $4.0 \%, 8.1 \%$ respectively compared to Jinong No. 4. E had a positive promotional effect on seed germination 
and seedling growth. So E was the best formulation, named after LSCA.

It can be seen from Table 2, these results were stabilized and consistent with those in Table $\mathbf{1}$.

These results showed that seed coating agents played a significant role in improving germinating tendency, germination rate and inhibitory rate, but the efficiency of LSCA was obviously superior to Jinong No. 4.

\subsubsection{Optimization Experiments in the Laboratory}

Based on the best formula of the seed coating agent LSCA, changing two main factors such as $\mathrm{pH}$ and the dilution to confirm the optimum conditions of seed coating agent, so that the new agent can achieve the best effect and improve the price-performance ratio.

\subsubsection{Influence of $\mathrm{pH}$ Value of Seed Coating Agent}

Influence of $\mathrm{pH}$ value (the range of 4.0 - 7.0) of seed coating agent was shown in Table 3.

As can be seen in Table 3, the best effects of germination tendency, germination rate and inhibitory rate were observed at $\mathrm{pH}$ 6.0. From 4.0 to 6.0, the higher the $\mathrm{pH}$ value was, the higher main parameters, and they reached the maximum at $\mathrm{pH}$ 6.0. When $\mathrm{pH}$ was above 6.0 , with the increasing of the $\mathrm{pH}$ value, they declined. Therefore the best $\mathrm{pH}$ value of corn seed coating agent was 6.0.

Table 1. The preliminary experimental results of the seed coating agents in the laboratory.

\begin{tabular}{cccc}
\hline Treatments & GT (\%) & GR (\%) & IR (\%) \\
\hline A & $72.5 \mathrm{c}$ & $86.4 \mathrm{~b}$ & $80.3 \mathrm{c}$ \\
B & $77.2 \mathrm{~b}$ & $89.8 \mathrm{~b}$ & $83.7 \mathrm{c}$ \\
C & $80.2 \mathrm{a}$ & $92.4 \mathrm{a}$ & $86.8 \mathrm{~b}$ \\
D & $83.6 \mathrm{a}$ & $94.3 \mathrm{a}$ & $89.5 \mathrm{~b}$ \\
E & $85.3 \mathrm{a}$ & $93.6 \mathrm{a}$ & $92.3 \mathrm{a}$ \\
F & $80.5 \mathrm{a}$ & $92.7 \mathrm{a}$ & $91.2 \mathrm{a}$ \\
G & $77.4 \mathrm{~b}$ & $90.1 \mathrm{a}$ & $88.5 \mathrm{~b}$ \\
H & $75.6 \mathrm{bc}$ & $88.4 \mathrm{~b}$ & $85.8 \mathrm{~b}$ \\
Jinong No. 4 & $76.9 \mathrm{~b}$ & $88.7 \mathrm{~b}$ & $84.2 \mathrm{c}$ \\
CK & $68.5 \mathrm{~d}$ & $76.4 \mathrm{c}$ & 0 \\
\hline
\end{tabular}

Averages in column separated by Duncan's new multiple range test, 5\% level. A-H: seed coating agents self-made; Jinong No. 4: a conventional seed coating agent; CK: blank control. GT: Germinating tendency; GR: Germination rate; IR: Inhibitory rate.

Table 2. The preliminary experimental results of the seed coating agents in the laboratory.

\begin{tabular}{cccc}
\hline Treatments & GT (\%) & GR (\%) & IR (\%) \\
\hline LSCA & $88.6 \mathrm{~b}$ & $94.8 \mathrm{a}$ & $93.6 \mathrm{a}$ \\
Jinong No.4 & $79.5 \mathrm{~d}$ & $87.1 \mathrm{~b}$ & $85.6 \mathrm{bc}$ \\
CK & $78.6 \mathrm{~d}$ & $85.5 \mathrm{bc}$ & - \\
\hline
\end{tabular}

These results are consistent with those reported by Jun-ang [17] that the optimal pH range was between 5.3 and 6.0 for the highest antifungal activity. This increase in $\mathrm{pH}$ was due to the increased consumption of $\mathrm{H}^{+}$ions in solution by the protonation of the free amine groups of polysaccharide [18]. When the $\mathrm{pH}$ value was 6.0 , the protective film on the surface of the seeds combined with seed coat more tightly and did not change various functions of seed inner, so when the $\mathrm{pH}$ value was 6.0, the film had better permeability which can guarantee plants supplying ample oxygen and water, and creating a beneficial condition for the better growth of seeding.

\subsubsection{Influence of the Dilution of Seed Coating Agent}

Results of the experiment in the lab showed different proportion of agent and seeds had different influence on corn seedling growth in Table 4.

It can be seen from Table 4, the effect on sprout potential, germination rate of 1:30, 1:40 was lower than that of CK, especially at 1:30, the agent restrained the growth of seedings, showing obviously a series of signs of hidebound symptoms such as shorter seedling and stem thin. When at 1:50, 1:60, 1:70, the main parameters of LSCA was higher3 times than that of $\mathrm{CK}$ and the growing and leaf color of seedings were consistent. Therefore, 1:50 was the best proportion. When at 1:50, the germination

Table 3. The influence of $\mathrm{pH}$ on the main performance parameters of seed coating agent.

\begin{tabular}{ccll}
\hline $\mathrm{pH}$ & GT (\%) & GR (\%) & IR (\%) \\
\hline 4.0 & $74.5 \mathrm{~d}$ & $82.5 \mathrm{c}$ & $83.6 \mathrm{c}$ \\
4.5 & $78.9 \mathrm{~d}$ & $86.5 \mathrm{~b}$ & $86.3 \mathrm{~b}$ \\
5.0 & $82.6 \mathrm{c}$ & $89.9 \mathrm{~b}$ & $88.5 \mathrm{~b}$ \\
5.5 & $86.6 \mathrm{~b}$ & $91.7 \mathrm{a}$ & $91.5 \mathrm{a}$ \\
6.0 & $88.6 \mathrm{~b}$ & $93.7 \mathrm{a}$ & $93.6 \mathrm{a}$ \\
6.5 & $85.6 \mathrm{bc}$ & $91.4 \mathrm{a}$ & $92.9 \mathrm{a}$ \\
7.0 & $82.6 \mathrm{c}$ & $90.6 \mathrm{a}$ & $90.2 \mathrm{a}$ \\
\hline
\end{tabular}

Averages in column separated by Duncan's new multiple range test, 5\% level.

Table 4. Compare of germination energy and germination rate in different proportion of seed.

\begin{tabular}{cccc}
\hline The dilution of LSCA & GT (\%) & GR (\%) & IR (\%) \\
\hline $1: 30$ & $84.9 \mathrm{c}$ & $89.9 \mathrm{~b}$ & $89.5 \mathrm{~b}$ \\
$1: 40$ & $86.6 \mathrm{~b}$ & $91.7 \mathrm{a}$ & $91.3 \mathrm{a}$ \\
$1: 50$ & $88.6 \mathrm{~b}$ & $94.8 \mathrm{a}$ & $92.9 \mathrm{a}$ \\
$1: 60$ & $87.5 \mathrm{~b}$ & $92.6 \mathrm{a}$ & $90.5 \mathrm{a}$ \\
$1: 70$ & $85.6 \mathrm{bc}$ & $90.6 \mathrm{ab}$ & $87.6 \mathrm{~b}$ \\
CK & $82.6 \mathrm{c}$ & $86.5 \mathrm{~b}$ & - \\
\hline
\end{tabular}

Averages in column separated by Duncan's new multiple range test, 5\% level. 
rate was up to $94.8 \%$, which displayed obviously to promote sprout and growth of seedings. It can be explained that when the proportion was 1:50, the protective film provides the favorable conditions for seed germination, growth, and plays significant role in maintaining bactericidal and insecticidal effect.

\subsubsection{Antifeedant Effect of Seed Coatings}

Results of antifeeding test showed that LSCA had an excellent antifeedant effect on selective antifeedant rate by observing experimental process and analysing of weight. According to the observation, the artificial feed containing LSCA was rarely bitten, while the artificial feed without LSCA (CK) was nearly eaten up. From Table 5, it showed when the proportion of LSCA was $15 \%, 10 \%, 5 \%$ on cutworm, the antifeedant rates were respectively $87.4 \%, 70.9 \%$ and $48.3 \%$. All of those indicated the antifeedant effect of LSCA was increased with increasing dosage of LSCA.

\subsubsection{Results of Acute Toxicity Test}

Results of acute toxicity test showed there were significant differences in the median lethal dose $\left(\mathrm{LD}_{50}\right)$ between LSCA and Jinong No. 4 (Table 6).

In the acute oral toxicity test, rats infected with a high dosage of Jinong No. 4 exhibited toxic symptoms after 3 6 min such as systemic muscle spasm, salivation, and even convulsions, and sticky nasal and ocular secretions in the 12 hours before death. The rats infected with low dosages still showed a sign of slight muscle spasm. However, the rats infected with LSCA didn't exhibit the previously mentioned symptoms and exposured to a low level. The datas showed that the acute oral $\mathrm{LD}_{50}$ and acute dermal $\mathrm{LD}_{50}$ in female rats were $607 \mathrm{mg} \cdot \mathrm{kg}^{-1}$ and $2106 \mathrm{mg} \cdot \mathrm{kg}^{-1}$, respectively. In the acute skin toxicity test, the rats were observed consecutively for two weeks when they were infected with the toxicant By safety experiment, we see that the acute toxicity of Jinong No. 4 was significantly higher (about 2 times) than that of LSCA. Therefore, the novel seed-coating agent LSCA was safe for human and meets the requirements of the environment protection during usage and disposal.

\subsubsection{The Comparative Result of Field Trials}

The comparative result was shown in Table 7.

Results of field trial showed that LSCA noticeably improved obviously the main performance indices such as the germination index, seedling rate (Table 7), when comparing with Jinong No. 4, the germination rate and per ha yield of LSCA were increased by $5.6 \%$ and $9.5 \%$ respectively; when compared to the uncoated corn seed (CK), and they were enhanced by $6.0 \%$ and $13.6 \%$ respectively, while the cost was declined by $18.75 \%$. It had indicated that the germination energy and germination rate in the laboratory were consistent with the trend of increasing yield in field experiment.

Table 5. The experimental result of antifeedant effect of the seed coating agents.

\begin{tabular}{cccccc}
\hline Treatment & Dosage of LSCA (\%) & Weight of AF (g) & Weight of AF in 48 h (g) & Feeding volume (g) & AF (\%) \\
\hline \multirow{2}{*}{ LSCA } & 15 & 5.488 & 5.193 & 0.294 & $87.4 \mathrm{a}$ \\
& 10 & 5.693 & 4.966 & 0.677 & $70.9 \mathrm{~b}$ \\
CK & 5 & 6.267 & 4.963 & 1.204 & $48.3 \mathrm{c}$ \\
\hline
\end{tabular}

Averages in column separated by Duncan’s new multiple range test, 5\% level. AF means artificial feed; LSCA means the novel seed coating agent; CK means the blank control.

Table 6. The result of the security test in rats.

\begin{tabular}{|c|c|c|c|c|}
\hline \multirow{2}{*}{ Experimental Groups } & \multicolumn{4}{|c|}{ Results of acute toxicity test } \\
\hline & Aot $\mathrm{LD}_{50} / \mathrm{mg} \cdot \mathrm{kg}^{-1}$ & $\mathrm{TC}$ & Ast $\mathrm{LD}_{50} / \mathrm{mg} \cdot \mathrm{kg}^{-1}$ & $\mathrm{TC}$ \\
\hline \multirow{2}{*}{ LSCA } & 798 (Male) & Slight & 2239 (Male) & Slight \\
\hline & 607 (Female) & Slight & 2106 (Female) & Slight \\
\hline Jinong No.4 & 127 (Female) & Moderate & 1554 (Female) & Moderate \\
\hline
\end{tabular}

Acute oral toxicity grading scale: 1) Slightly toxic: $\mathrm{LD}_{50}>500 \mathrm{mg} \cdot \mathrm{kg}^{-1}$; 2) Moderately toxic: $\left.50<\mathrm{LD}_{50}<500 \mathrm{mg} \cdot \mathrm{kg}^{-1} \mathrm{~g} ; 3\right) \mathrm{Highly}$ toxic: $\mathrm{LD}_{50}<50 \mathrm{mg} \cdot \mathrm{kg}^{-1}$. Acute dermal toxicity grading scale: 1) Slightly toxic: $\mathrm{LD}_{50}>2000 \mathrm{mg} \cdot \mathrm{kg}^{-1}$; 2) Moderately toxic: $200<\mathrm{LD}_{50}<2000 \mathrm{mg} \cdot \mathrm{kg}^{-1}$; 3) $\mathrm{Highly}$ toxic: $\mathrm{LD}_{50}<200$ $\mathrm{mg} \cdot \mathrm{kg}^{-1}$. 
Table 7. The investigation results of the field trial.

\begin{tabular}{lccc}
\hline \multicolumn{1}{c}{ Measurement Indicators } & LSCA & Jinong No. 4 & CK \\
\hline Germination index & 11.2 & 10.8 & 10.2 \\
Seedling rate (\%) & 96.4 & 92.5 & 91.9. \\
The length of function leaf (cm) & 96 & 84 & 83 \\
The thick of stem (cm) & 3.6 & 2.7 & 2.5 \\
The rate of infected plant (\%) & 0 & 5.3 & 25.6 \\
Yield $\left(\mathrm{kg}^{-1} \mathrm{ha}^{-1}\right)$ & 986 & 892 & 852 \\
Cost $\left(\mathrm{US} \$ \cdot \mathrm{kg}^{-1}\right)$ & 1.3 & 1.6 & \\
Toxicity & Slight & Moderate & \\
\hline
\end{tabular}

Averages in column separated by Duncan's new multiple range test, 5\% level.

\subsection{Discussion}

\subsubsection{The Mechanism of Insect Prevention}

The most important difference between LSCA and Jinong No. 4 was LSCA used PC as the main ingredient, which can improve plant pest and disease resistance capability, and promote plant's growth, crop yield and quality $[19,20]$. When the plant is attacked by pest, PC as an inducer stimulates plants to produce a series of defense reactions and produce secondary structure (e.g. periderm, corpus callosum, glue sluggish body, invade fill body, excise, halo, etc.) and some functional molecules (e.g. plants defend element, phenolic compounds, duration of related proteins, pathogens, enzyme inhibitors, etc.), which are inexistent before stimulating. These substances directly or indirectly suppress chemical sensors of insect mouthpart, and block the nerve conduction, make its information transfer of feeding behavior interrupted, or causing abnormal discharge from animals to get correct taste of information and not to eat [21-24]. So LSCA controls pests through the approach of repelling pests and enhancing the immunity of seeds, instead of poisoning pests. Finally pest lose taste function and refuse feeding reaction.

In addition, if PC is used in advance, plants will mistake pest coming so that they can produce resistant material (phenylalanine solution ammonia enzyme (PAL), peroxidase (PO) and polyphenol oxidase (PPO), phytoalexin etc, protein related to the disease such as chitinase, and beta arene glucan enzyme etc.), and thus act the genes of plant resistance and make plant produce system antibody, which can keep a high level for a long time to repel pests [25-27]. PC as an inducer using in the earlier stage crop growth is better than used in the later period.

The inducible resistance function of PC is like to hit the precaution for plants, which makes plants less ill or no, thus promote plant's growth, crop yield and quality.

\subsubsection{The Mechanism of Yield Increase}

The field experiment results showed that seeds coated with PC had better resistance to smut fungus and higher germination percentage and higher crop yields than the control. The first main reason is the mentioned-above mechanism of insect prevention, and another is that PC can enhance the resistance against smut fungus and has a repellent effect to the pests in the soil, so that the plants are safe from threats and damage by disease and have a positive seedling growth and the fruits of harvest [2830].

The second reason contributes to PC of LSCA, which has the ability of forming a dense protective film on the surface layer of seeds. The film increases the brightness of the coated seeds. In this case, the fungicide was glued on the surface of the seeds, it is an advantage, since it allows the continuous contact of the fungicide with the seed surface and increased the resistance of the fungicide to be removed by the wind or rain. Thus, the agent was acting not only as antimicrobial coating itself but also as a carrier system of agrochemicals [31,32].

The film has a good selective permeability which can prevent oxygen from entering the film, restrict loss of $\mathrm{CO}_{2}$, and maintain a high concentration of $\mathrm{CO}_{2}$ in the film [33-35], so as to restrain the seed's respiration, maintain the seed moisture and absorb the soil moisture, and cut off excessive soil moisture to prevent the seed from corrupting. In short the film can provide a good growth environment for seeds germination and growth and make the internal nutrient consumption of seeds fall to the lowest possible level [36-38]. It is just that this layer of natural polymer membranes plays a vital role on corn yield and antifeedant effect.

The third reason contributes to the corn yield increase may be the effect of the trace elements and fertilizer contained in LSCA. The trace fertilizer can increases the activity of an enzyme and provide abundant nutrient sources for germ growing.

\section{CONCLUSIONS}

The formula was as follows: $1 \%$ PC $56 \%$, sodium hydroxide $5 \%$, trace fertilizers $22 \%$, trace element $1.5 \%$, active ingredients $1 \%$, filmogen $4 \%$, plant growth regulator $2 \%$, water $6.5 \%$, natural pigment $2 \%$. In the process of preparation, the $\mathrm{pH}$ of the agent was adjusted to 6.0 , and the dilution was 1:50. The results showed that a novel formulation had increased the yield by about $13.6 \%, 9.5 \%$ over that of CK and Jinong No. 4, respectively. Furthermore, the cost of LSCA was $18.75 \%$ less and the toxicity was lower than that of Jinong No. 4. So it is safe, non-polluting, and has significant economic and environmental benefits. 


\section{ACKNOWLEDGEMENTS}

We express the appreciation to Wuhan Science and Technology Bureau of China for financial support (No. 201120922303). We also thanks the State Key Laboratory of Crop Biology of Shandong Agricultural University. A special acknowledgement is given to Wuhan University of Technology for experimental conditions and technical support.

\section{REFERENCES}

[1] Majeti, N.V. and Ravi, K. (2000) A review of chitin and chitosan applications. Reactive and Functional Polymers, 46, 1-27. doi:10.1016/S1381-5148(00)00038-9

[2] Russ, W.G. and David, W.A. (2005) Influence of sowing date on emergence characteristics of maize seed coated with a temperature-activated polymer. Agronomy Journal, 97, 1543-1550. doi:10.2134/agronj2005.0054

[3] Freeborn, J.R., Holshouser, D.L., Alley, M.M., Powell, N.L. and Orcutt, D.M. (2001) Soybean yield response to reproductive stage soil-applied nitrogen and foliar-applied boron. Agronomy Journal, 93, 1200-1209. doi:10.2134/agronj2001.1200

[4] Bardin, S.D., Huang, H.C. and Moyer, J.R. (2004) Control of pythium damping-off of sugar beet by seed treatment with crop straw powders and a biocontrol agent. Biological Control, 29, 453-460.

doi:10.1016/j.biocontrol.2003.09.001

[5] Ehsanfar, S. and Modarres-Sanavy, S.A.M. (2005) Crop protection by seed coating. Communications in Agricultural and Applied Biological Sciences, 70, 225-229.

[6] Shi, J. and Liu, Z. (2002) Prospects of the application of seed-coating techniques to medicinal plants. Journal of Chinese Medicinal Materials, 25, 69-71.

[7] Wang, Z.Q., Ning, M.Y. and He, Y.Q. (2005) The development, promotion and application prospects of seed coating technology in China. Seed Sales Representative, 4, 15-16.

[8] TeKrony, D.M. (2006) Seeds: The delivery system for crop Science. Crop Science, 46, 2263-2269. doi:10.2135/cropsci2005.12.0445

[9] Da, Z.J. (2006) Development and application of the seed coating agent. Agriculture Mark Weekly, 25, 30-32.

[10] Xie, H.L. and Xu, G.M. (2008) Suspension property of Gemini surfactant in seed coating agent. Journal of Dispersion Science and Technology, 29, 496-501. doi:10.1080/01932690701728684

[11] Ye, L., Zhu, J.H., Wang Q.P. and Wang, W. (2001) Study on the acute toxicity and contact allergenic activity of 6 seed treatment preparations. Acta Universitatis Medicinalis Anhui, 36, 279-281.

[12] Wang, W., Wang, Q.P. and Zhu, J.H. (2001) Study on the acute toxicity and contact allergenic activity of 6 seed treatment preparations. Acta Universitis Medicinalis Aahui, 36, 279-281.

[13] Zhu, Z.L., Gong, R.Z. and Han, Z.H. (2003) The toxicity of pesticides on birds and the safety evaluation. Rural Eco-Environment, 19, 53-57.

[14] Wu, X.H., Zhang, W.H. and Liu, P.F. (2003) Research and development trend of the seed coating agent in China. Plant Protection and Promotion of Technology, 10, 3638.
[15] Zhao, B. and He, S.J. (2005) The microbiological experiments. Science Publishers, Beijing, 128-130.

[16] Wang, R.M. and Yan, J.Z. (2005) Seed film coating with uniconazole improves rape seeding growth in relation to physiological changes under waterlogging stress. Plant Growth Regulation, 47, 75-81

[17] Jun-Ang, L., Aixian, J., Guoying, Z., Yuan, H. (2009) Antifungal activity of chitosan against coll etotrichumgloes porioides. Bioinformatics and Biomedical Engineering, $\mathrm{e} 4$.

[18] Cho, J., Heuzey, M.C., Bgin, A. and Carreau, P.J. (2006) Chitosan and glycerophosphate concentration dependence of solution behaviour and gelpointusing small amplitude oscillatoryrheometry. Food Hydrocolloids, 20, 936-945. doi:10.1016/j.foodhyd.2005.10.015

[19] Xiong, Y.F., Zou, Y.B., Wen, Z.Y., Jiang, J.A., Xiong, H.R. and Tang, Q.Y. (2004) Effects of rice seed coating agent on seedling growth, enzyme activities and internal hormanes of rice. Scientia Agricultura Sinicu, 37, 16111615.

[20] Zhang, H.Q. (2002) Studies and developing prospects of rice seed coating agent. Crop Research, 16, 350-353.

[21] Bian, Y.P. (2000) Exposurer corn seedling diseases and insect pests prevention. Effect of early submitted test Journal of Agriculture, Science and Technology, 4, 2629.

[22] Shibuya, N. and Minami, E. (2001) Oligosaccharide signalling for defence responses in plant. Physiological and Molecular Plant Pathology, 59, 223-233. doi:10.1006/pmpp.2001.0364

[23] Chen, H.P. and Xu, L.L. (2005). Progress of study on chitosan in regulating plants' growth and eliciting plants' defense responses. Acta Botanica Yunnanica, 27, 613619.

[24] Brooker, N.L., Lagalle, C.D., Zlatanic, A., Javni, I. and Petrovic, Z. (2007). Soy polyol formulations as novel seed treatments for the management of soil-borne diseases of soybean. Communications in Agricultural and Applied Biological Sciences, 72, 35-43.

[25] Ma, P.P. and He, L.Q. (2001) Progress of chitosan in suppression of plant diseases. Natural Product Research and Development, 13, 82-86.

[26] Weller, D.M. (2002) Biological control of soilborne plant pathogens in the rhizosphere with bacteria. Annual Review of Phytopathology, 26, 379-407. doi:10.1146/annurev.py.26.090188.002115

[27] Chaton, P.F., Lempérière, G., Tissut, M. and Ravanel, P. (2008) Biological traits and feedingcapacity of Agriotes larvae (Coleoptera: Elateridae): A trial of seed coating to control larval populations with the insecticide fipronil. Pesticide Biochemistry and Physiology, 90, 97-105. doi:10.1016/j.pestbp.2007.09.001

[28] Kim, C.H, Kim, S.Y. and Choi, K.S. (1997) Symthese and antibacterial activity of water-soluble chitin derivatives. Polymers for Advanced Technologies, 8, 319-325. doi:10.1002/(SICI)1099-1581(199705)8:5<319::AID-PA T645>3.0.CO;2-G

[29] Liu, X.F., Guan, Y.I. and Yang, D.Z. (2000) Antibacterial action of chitosan and carbixy-methylated chitosan. Journal of Applied Polymer Science, 79, 1324-1335.

[30] Issam, S.T., Adele, M.G. and Adele, C.P. (2005) Chitosan polymer as bioactive coating and against Aspergillus ni- 
ger contamination. Journal of Food Science, 70, 100104.

[31] Qun, J., Wang, R.M., Yan, J.Z. and Hu, J. (2005) Seed film coating with uniconazole improves rape seeding growth in relation to physiological changes under waterlogging stress plant. Plant Growth Regulation, 47, 75-81. doi:10.1007/s10725-005-2451-z

[32] Khalid, Z., Beatriz, U. and JuanI, M. (2010) Application of bioactive coatings based on chitosan for artichoke seed protection. Crop Protection, 29, 853-859. doi:10.1016/j.cropro.2010.03.002

[33] Tanabe, T. and Oachibana, A. (2002) Preparation and characterization of reration-chitosan composite film. Biomaterials, 23, 817-825. doi:10.1016/S0142-9612(01)00187-9

[34] Zhou, T., Liu, J. and Zhou, X.M. (2003) The effect of chitosan on the physiology and yield increase of crop plants. Jilin Nomal University Journal, 5, 18-21.

[35] Robani, H. (2004) Film-coating of horticultural seed. HortTechnology, 4, 104-105.

[36] Rabea, E.I., Badawy, M.E.T., Stevens, C.V., Smagghe, G. and Steurbaut, W. (2003) Chitosan as antimicrobia agent: Applications and mode of action. Biomacro-Molecules, 4, 1457-1465. doi:10.1021/bm034130m

[37] Furbank, R.T., White, R. and Palta, J.A. (2004) Internal recycling of respiratory $\mathrm{CO}_{2}$ in pods of chickpea (Cicer arietinum L): The role of pod wall, seed coat, and embryo. Journal of Experimental Botany, 55, 1692, 16871696.

[38] Richard, M. (2005) Application of latex emulsion polymers in seed coating technology. Pesticide Formulations and Applications Systems, 23, 55-67. 